\title{
How leadership within an organization influences a quality service
}

\begin{abstract}
The purpose of this paper is to discuss leadership influences a quality service in healthcare organization. Leadership is a way of sharing power and ensuring that expertise and leadership are interrelated at every level in every task; create positive culture in health care organization. Positive leadership culture focus on inspiring vision; clear objectives; supportive management; high levels of staff engagement; the responsibility of learning and innovation; teamwork and co-operation across boundaries. Results showed that the leadership influenced service quality adherence and service performance. Conclusion Leadership build appropriate and unique organizational cultures and a high-performing team, which provide high quality service to patients in healthcare organization.
\end{abstract}

Keywords: leadership, psychological empowerment, safety culture, service quality
Volume 3 Issue 2 - 2018

\author{
Chunmei Lu,' Li Zhang² \\ 'First People's Hospital of Foshan, Affiliated with Sun Yat-Sen \\ University, China \\ ${ }^{2}$ Department of Nursing, Affiliated with Sun Yat-Sen University, \\ China
}

Correspondence: Li Zhang, Department of Nursing, The First People's Hospital of Foshan, Affiliated with Sun Yat-Sen University, Lingnan Road, Chancheng District, Foshan, China, Tel +0086-18038866|58, Email Icmei@fsyyy.com

Received: February 21, 2018| Published: April 23, 2018

\section{Introduction}

High quality service is the key factor for maintaining loyal customers. According to Quality Improvement Division, ${ }^{1}$ the definition of healthcare quality is broken down into six domains: "Safety, Effectiveness, Patient-centred, Timeliness, Efficiency, Equity"; quality improvement combines all the resources, providing a better experience of care which creates better patient outcomes. The King's Fund ${ }^{2}$ report suggests that medical staff should adopt a culture of putting the patient first; this promotes a culture of learning and improvement, which helps the organization focus on enhancing quality and safety. Good leaders shape the culture and can create a positive environment modelling the behaviour for the organization. ${ }^{3}$ Ellis \& Abbott ${ }^{4}$ state the characteristics of good leadership culture include: shared values, clear direction, concentration on team work, good communication and feedback for functioning as a learning team. In other words, improving quality service must focus on nurturing appropriate and unique organizational cultures and building a highperforming team so that they can face the unpredictable, everchanging situations. ${ }^{5}$

\section{The concept of leadership}

West et al. ${ }^{5}$ notes that leadership describes a way of sharing power and ensuring that expertise and leadership are interrelated at every level in every task. Effective leaders focus on strategy to develop an organizational culture of high-quality service and ensuring it is implemented. Indeed, West et al..$^{5}$ underlines key cultural characteristics as following: inspiring vision; clear objectives; supportive management and leadership; high levels of staff engagement; the responsibility of learning and innovation; teamwork and co-operation across boundaries. To achieve this, leaders ensure that everyone takes responsibility for the organization as a whole, not just on their own individual ability or task. According to Locke \& Latham, ${ }^{6}$ vision and mission in leadership should provide a direction for staff and must be translated into clear objectives at all levels of the organization. Leaders should judge whether subordinates really believe in a goal and whether their ability can achieve it. Leaders should not only express the organization's values or vision, but also follow the actions necessary to make it a reality. ${ }^{7}$ Fang-guo ${ }^{8}$ notes that dynamic interplay can inspire individual's potential capability and working demand.

\section{The application of leadership}

Additionally, West et al. $^{5}$ claimed that leaders and managers should create positive culture in health care organization. Buggins ${ }^{2}$ "Health care organizations are often not very supportive places to work." All leaders should give staff adequate time and space to think, review, and learn from experience. When leaders really care for staff they are equipped to provide high quality care to patients. Comparing the cultural characteristics of high- and low-performing organizations, Mannion et al. ${ }^{7}$ found that the better performing organizations had divided power and responsibility with a shared and open style of team work culture and staff engagement; the poorperformers had "an underdeveloped and powerless tier of middle management". In addition, Akerjordet \& Severinsson ${ }^{9}$ demonstrated that encouraging staff to participate in decision-making can create a positive environment, which will lead to subordinates' well-being.

Another important aspect that influences service performance is psychological empowerment. Spreitzer ${ }^{10}$ defines four characteristics of psychological empowerment: work meaning, self-efficiency, selfdetermination and impact. Working meaning indicates a work target to judge their own value; self-efficiency indicates one believes staff can finish the job by their own ability; self-determination indicates individual autonomy; and impact means working achievement and influence in the organization. Fang-guo ${ }^{8}$ observed that when service staff realizes the job is valuable and gain self-achievement, their job autonomy develops and the trust relationship between staff and customers is established. Staff can offer flexible and individual service for customers, even over the customer's expectation. This is a good way to achieve customer satisfaction. Even when working mistakes happen, employees can handle the problems with flexibility and offer timely service to change the situation.

Therefore, The King's Fund ${ }^{2}$ reports the higher the level of staff commitment, the higher the level of patient satisfaction. Maintaining a culture of high-quality service involves all staff promoting continuous learning and improvement of patient care. The National Advisory 
Group on the Safety of Patients in England ${ }^{11}$ declares staff should provide 'top to bottom and end to end' care and take leadership responsibility for improving quality. Furthermore, Eckert et al. ${ }^{12}$ assert that the aim of focusing on learning from involved patients and carers is beneficial for solving chronic system problems, especially adapt to change and integrate services. Additionally, if medical staff keep respect the individual's privacy and dignity, it would be beneficial in fulfilling patient's social needs and expectations. ${ }^{3}$ Good leadership teams appreciate and coach staff and support them in adapting new workflow processes and technology. ${ }^{13}$

Further reports ${ }^{11}$ place the quality of patient safety above all other aims. Caring staff engage, empower, hear the patients' voice at all times and foster whole-hearted care to improve and develop the service they are providing. Muls et al. ${ }^{3}$ also note positive safety culture focus on: shared values; safe care delivery; zero-tolerance for substandard care; empowering front-line staff and recognising staff for their contribution. The King's Fund ${ }^{2}$ says that leadership development is important for nurturing an organizational culture which ensures that the values of "patient-centred care" are known and understood by all levels of staff. Staff should not only focus on what to do and when to do it, they also need to develop communication skills and observation capability. The above provide the evidence for exploring different ways to ensure the services they are providing are culture sensitive, safety focused and responsive to the needs of the patient. However, without leading through a model, the staff will have difficulty in achieving the standards that the leaders expect; sometimes the team may even become dysfunctional. ${ }^{14}$ For instance, The King's Fund ${ }^{2}$ mention shocking failures of management that occurred at the Mid Staffordshire NHS Foundation Trust in the UK and resulted in hundreds of patients being harmed unnecessarily. Openness to learning from others and striving for best practice are essential factors of a healthy organizational culture. The King's Fund ${ }^{2}$ declares that the example at Mid Staffordshire Hospital, they should learn some experience from Mayo Clinic in the United States. Mayo Clinic culture expresses "The needs of the patient come first", this value is powerfully believed from the chief executive down, and all staff focus on patient experience and clinical quality; any poor practice and underperformance are under a zero-tolerance policy. ${ }^{2}$

\section{Discussion}

Quality Improvement Division ${ }^{1}$ point out the capability to measure and analyse information is essential to improving service quality. Leaders collect information related to a service and analyse the data, in order to identify underperformance. The information includes: patient experience and outcomes; sharing and displaying data for a team; providing assurance; supporting improvement and building data collection into routine work. All these influence staff behaviour as well as achieving success in improving quality. ${ }^{1}$ Health Information and Quality Authority ${ }^{15}$ state that the head authority has responsibility for: building up person centred-care standards which are based on evidence and best clinical practice; ensuring the delivering of care is responsive to individuals' needs; monitoring the quality and safety, making sure the standards are clinically effective in improving patient's outcomes; preventing and minimising harm to patients and learning from errors; sharing health information about the delivery and performance; and giving timely feedback by evaluating the effectiveness of drugs, equipment and promotion activities. Those factors play a positive role in quality service and build up the trust relationship between patients and medical staff. ${ }^{16}$

\section{Conclusion}

As described above, leaders instil values of "patient-centred care" and enable staff to do their jobs effectively. They achieve high staff engagement at all levels by providing accessible support and a positive environment. Most importantly, leaders monitor the quality and safety of service, making sure the standards are clinically effective; they share health information and give timely feedback on staff performance to promote constant development. Moreover, fostering leadership throughout health care would highlight the continued growth of an organization. Change is continuous, so organizational culture and leadership should go hand in hand because both are critical to improve quality service. Finally, when the right leadership and culture is formed, proper quality service will be delivered and it will benefit all staff and patients. Creativity, adaptability and flexibility are as important as perseverance and passion for the organization in the long run.

\section{Author contribution}

The author make all contribution associated with this article. The author sets up the conception and design of the study, collect and analysis the data, drafting and finish the article, and approves the version to be submitted.

\section{Ethical approval}

None.

\section{Funding}

This research received no specific grant from any funding agency in the public, commercial or not-for-profit sectors.

\section{Acknowledgements}

This study is completed during the first author study in Ireland. The authors appreciate the suggestions and comments provided by Professor Gerardina Harnett in Institute of Technology, Tralee. Also to thank the Library of Institute of Technology, Tralee, or their help in finding the relevant literatures, this made this integrated review possible.

\section{Conflict of interest}

The authors did not have a conflict of interest in the preparation of this paper.

\section{References}

1. https://www.hse.ie/eng/about/Who/qualityandpatientsafety/MedicalDevices/decontamination/Quality-Improvement-Framework.pdf

2. www.kingsfund.org.uk/publications/patient-centred-leadership

3. Muls A, Dougherty L, Doyle N, et al. Influencing organizational culture: a leadership challenge. British Journal of Nursing. 2015;24(12):633-638.

4. Ellis P, Abbott J. Leadership and management skills in healthcare. British Journal of Cardiac Nursing. 2013;8(2):96-99. 
5. West M, Eckert R, Steward K, et al. Developing collective leadership for health care. London: The King's Fund. 2014.

6. Locke EA, Latham GP, editors. New developments in goal setting and task performance. Routledge. 2013.

7. Mannion R, Davies HTO, Marshall MN. Cultural characteristics of "high" and "low" performing hospitals. Journal of health organization and management. 2005;19(6):431-439.

8. Fang GS. Multilevel model of transformational leadership and service quality: Testing mediation role of psychological empowerment. International Conference on Management Science \& Engineering. 20:1355-1362.

9. Akerjordet K, Severinsson E. Emotionally intelligent nurse leadership: a literature review study. Journal of Nursing Management. 2008;16(5):565577.

10. Spreitzer GM. Psychological empowerment in the workplace: Dimensions, measurement, and validation. Academy of management Journal. 1995;38(5):1442-1465.
11. www.gov.uk/government/publications/berwick-review-into-patient-safety

12. Eckert R, West M, Altman D. et al. Delivering a Collective Leadership Strategy for Health Care. London: The King's Fund, Center for Creative Leadership. 2014.

13. Vanderboom CE, Scherb CA, Kirchner RB, et al. Leadership Strategies, An Interdisciplinary Team, and Ongoing Nurse Feedback: Ingredients for a Successful BCMA Project. Nursing Economics. 2016;34(3):117-25.

14. Bhargava P, Mohammed TLH. Three Simple Strategies for Effective Leadership. Current problems in diagnostic radiology. 2016;1(45):1.

15. file:///D:/Documents/Downloads/Safer-Better-Healthcare-Standards $\% 20$ (2).pdf

16. Mendes L, Jesus José GFM. Influence of leadership on quality nursing care. International journal of health care quality assurance. 2014;27(5):439450 . 